\title{
Language as a barrier to cancer clinical trial accrual: assessing consenting team knowledge and practices for cancer clinical trial consent among low English fluency patients
}

Jeanine N. Staples ${ }^{1 *}$, Jenny Lester², Andrew Li², Christine Walsh², Ilana Cass' ${ }^{2}$ Beth Y. Karlan², Catherine Bresee ${ }^{2}$ and B. J. Rimel $^{2}$

\begin{abstract}
Background: Low English fluency in large culturally diverse institutions may contribute to meager minority accrual. Our objective was to: 1) Assess knowledge of proper consenting procedures among the research team when consenting a low English fluency patient. 2) Assess the enrollment rate of participants in cancer therapeutic trials who identify a preferred language other than English.

Methods: An anonymous web-based survey was distributed at a single institution to investigators, research staff and translator services to assess knowledge of consenting procedures. Patient enrollment data was retrieved from the clinical trials enrollment tracking system from January 2011 - October 2014 and matched to registration data indicating preferred language $(N=1521)$. The number and type of cancer cases from January 2011-October 2014 were retrieved from the institutional cancer registry and matched to registration data indicating preferred language.

Results: Although there are many organizational in-person and web-based trainings focused on the requirements for consenting low English fluency patients, members of the research team responded correctly to only $64.8 \%$ $(\sigma=24.6 \%)$ of the knowledge-based portion of the survey. Of the 12,538 index cancer cases indentified, $10 \%$ preferred a language other than English. Trial enrollment rates for cancer clinical trials were similar for English (13\%), Spanish (11\%), and, Armenian (10\%) speakers. Populations speaking Russian and Arabic had the lowest participation at $5 \%$ each.
\end{abstract}

Conclusions: In order to increase enrollment into clinical trials, institutions must explore more effective training opportunities for research staff, engage interpreters and adopt recruitment and study materials in different languages.

Keywords: Clinical trials, Disparities, Low English fluency

\footnotetext{
*Correspondence: js6qf@hscmail.mcc.virginia.edu

Past presentations: This paper was presented as a poster presentation at the

SGO Annual Meeting, San Diego, CA, March 2016.

'Division of Gynecology Oncology Department of Obstetrics and

Gynecology, University of Virginia, P.O. Box 800712, Charlottesville, VA 22908,

USA

Full list of author information is available at the end of the article
}

(c) The Author(s). 2018 Open Access This article is distributed under the terms of the Creative Commons Attribution 4.0 International License (http://creativecommons.org/licenses/by/4.0/), which permits unrestricted use, distribution, and reproduction in any medium, provided you give appropriate credit to the original author(s) and the source, provide a link to the Creative Commons license, and indicate if changes were made. The Creative Commons Public Domain Dedication waiver (http://creativecommons.org/publicdomain/zero/1.0/) applies to the data made available in this article, unless otherwise stated. 


\section{Background}

Clinical trials play an essential role in advancing our knowledge of cancer care, including the discovery and development of new preventative strategies, diagnostic tools and treatment options. Even with potential life changing benefits, subject accrual is often a challenging task. Only 3\% of adults participate in cancer therapeutic studies when $20 \%$ may be eligible [1-4]. Participation rates are even lower among ethnic and racial minorities [5-8]. Paradoxically, cancer morbidity and mortality rates are higher among these individuals [9]. There is a need for adequate representation of minority populations in clinical trials to ensure generalization of results, to learn about potential differences among groups and potentially improve outcomes for these individuals $[10,11]$. Nonetheless, from January 2003 to June 2005, white individuals comprised $88.6 \%$ of Cancer Clinical Trial participants [12]. There are a number of barriers to minority enrollment in clinical trials, including economic factors, lack of invitation, lack of awareness, mistrust, and communication issues, such as low literacy and language differences [9, 13-17].

The clinical cancer research community faces many challenges, and those related to physician-patient communication are often overlooked. Physician's lack of cultural competency, patient's lack of health literacy, and language barriers are factors that may influence patient participation. Language barriers present a unique challenge to certain high volume, diverse practices. Patients with low English proficiency may be overlooked for cancer clinical trials. Unfortunately, a number of US clinical trials require English proficiency for potential participants, automatically excluding those who do not speak the language [18]. On the other hand, those that are eligible may have a difficult time reading and understanding medical information, even when this is translated into their preferred language.

Cancer therapeutic studies often present an extremely complex consent form with many pages of text and tables. In an institution such as Cedars Sinai Medical Center, that provides access to over 100 different language interpretation services, there are working guidelines and best practice education available to research staff. This system endeavors to be an effective and reproducible system for consenting low English proficiency (LEP) patients, with a goal of enrolling $100 \%$ of eligible patients. However, there are several members of the team engaging with the patient regarding informed consent; the principal investigator or co-investigator and the research nurse and/or research coordinator. There are also translation service staff who are called upon to translate consents and consent discussions. Furthermore, as part of Cedars-Sinai Medical Center's Interpreter
Services, patients have access to MARTTI, which serves as an acronym for 'My Accessible Real-Time Trusted Interpreter,' a HIPPA-approved, two-way video and audio wireless connection to a certified medical interpreter. It is important for providers and research team members to anticipate and prepare language access needs for potential patients. The purpose of this study was to: 1) Assess knowledge of proper consenting procedures among research coordinators, principal investigators and interpreters when consenting a low English fluency patient; 2) Assess the patient enrollment rate in cancer therapeutic trials from January 2011 through October 2014 who identified a preferred language other than English.

\section{Methods}

Institutional Review Board (IRB) approval was obtained prior to study commencement. For Aim \#1, an anonymous web-based survey was distributed to principal investigators, co-investigators, research coordinators, research nurses and translator services at the Samuel Oschin Comprehensive Cancer Institution (SOCCI) at Cedars-Sinai Medical Center in Los Angeles, California. All research related staff were given the same set of questions. This consisted of five multiple-choice clinical scenario questions, three multiple-choice procedural knowledge questions, and nine questions eliciting personal practice methods utilizing a Likert scale (Included in Additional file 1: Appendix A). The survey was sent to a total of 98 individuals, including 58 principal and co-investigators combined, as well as 40 clinical research coordinators and research nurses. A separate web-based survey was sent to Translational Services staff, including two multiple-choice clinical scenarios and three questions eliciting previous experience with translating specifically for cancer clinical trials (Included in Additional file 2: see Appendix B). This survey was sent to a total of four members of the translating staff. Assessment of survey content validity was completed prior to distribution.

For Aim \#2, data were retrieved from the clinical trials enrollment tracking system from January 2011 - October 2014 and matched to patient registration data indicating preferred language $(N=1521)$. Study staff worked with SOCCI and the Oncore data collection system to determine the percentage of participants on clinical trials who have identified a language other than English on their face sheet. Our study included participants in all cancer clinical trials included in the above dates. De-identified data was retrieved from the Cedars-Sinai Cancer Registry to determine the number and type of index cancer cases from January 2011 - October 2014. This data was subsequently matched to patient registration data indicating preferred language. 


\section{Statistical analysis}

For Aim \#1, the rate of correct response for each survey question was computed as a percentage. Total score was computed as the percent of correct answers, where respondents skipped no more than 2 questions. Response rates among research nurses and clinical research coordinators were compared to that of principle and co-investigators. $P$-values were computed by Fisher's Exact Test for each individual question, and by Wilcoxon Rank Sum Test for the total score. For Aim \#2, enrollment rate analysis was performed using logistic regression, excluding "Others", with $p$-values adjusted by Tukey multiple comparison test. The enrollment rate for English-speaking patients was used as the reference.

\section{Results}

\section{Study staff survey findings}

The survey was sent to a total of 98 individuals, with a $54 \%$ response rate, yielding a total of 53 respondents, including18 principal investigators, 4 co-investigators, 19 research coordinators and 12 research nurses. Table 1 shows the rates of correct responses among all four groups for each clinical scenario or procedural knowledge question. The total score was computed as the percent of correct answers, where respondents skipped no more than 2 questions. The average score among all participants was $64.8 \%+/-24.6 \%$.

The research nurses and research coordinators collectively had a significantly higher correct response rate $(73.8 \%+/-20.5 \%)$ compared to the Principle and Co-Investigators $(51.4 \%+/-24.6 \% ; p=0.0033$, Table 1$)$. Correct response rates were highest for the questions eliciting appropriate signature requirements for the short

Table 1 Rates of Correct Responses to Study Survey

\begin{tabular}{|c|c|c|c|c|c|c|c|}
\hline \multirow{3}{*}{ Scenario 1} & \multirow{2}{*}{\multicolumn{2}{|c|}{$\frac{\text { Entire Cohort }}{(N=53)}$}} & \multirow{2}{*}{\multicolumn{2}{|c|}{$\begin{array}{l}\text { Nurses/CRC } \\
(N=31)\end{array}$}} & \multirow{2}{*}{\multicolumn{2}{|c|}{$\begin{array}{l}\mathrm{Pls} / \mathrm{Co}-\mathrm{Pls} \\
(N=22)\end{array}$}} & \multirow{3}{*}{$\begin{array}{l}\begin{array}{l}p- \\
\text { value }\end{array} \\
0.0514\end{array}$} \\
\hline & & & & & & & \\
\hline & $26 / 53$ & $49 \%$ & $19 / 31$ & $61 \%$ & & \\
\hline no & $21 / 46$ & $46 \%$ & 1 & $61 \%$ & $4 / 18$ & $22 \%$ & $0.0156^{*}$ \\
\hline o & $23 / 45$ & $51 \%$ & $17 / 27$ & $63 \%$ & $6 / 18$ & 33 & 0.07 \\
\hline Chit & $22 / 46$ & $48 \%$ & $18 / 28$ & $64 \%$ & $4 / 18$ & $22 \%$ & 0.0072 \\
\hline er & $34 / 44$ & $77 \%$ & $21 / 26$ & $81 \%$ & $13 / 18$ & $72 \%$ & $0.71 €$ \\
\hline 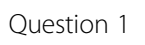 & $30 / 44$ & $68 \%$ & $21 / 26$ & $81 \%$ & $9 / 19$ & $50 \%$ & 0.070 \\
\hline uestion 2 & $44 / 45$ & $98 \%$ & $26 / 27$ & $96 \%$ & 18/18 & $100 \%$ & 0.9999 \\
\hline 2ucstiot & $36>>$ & $0 \%$ & $22 /$ & (1) & $14 /$ & $78-3$ & - \\
\hline \multirow[t]{2}{*}{ Total Score } & \multicolumn{2}{|c|}{$(n=45)$} & \multicolumn{2}{|c|}{$(n=27)$} & \multicolumn{2}{|c|}{$(n=18)$} & \\
\hline & \multicolumn{2}{|c|}{$64.8+/-24.6$} & \multicolumn{2}{|c|}{$73.8+/-20.5$} & \multicolumn{2}{|c|}{$51.4+/-24.6$} & $0.0033^{*}$ \\
\hline
\end{tabular}

Abbreviations: (CRC) Clinical Research Coordinator, $(P I)$ Principle Investigator * Indicates Nurses/CRC group is significantly greater than Pls/Co-PIs $(p<0.05)$ form, the Bill of Rights, HIPAA Authorization, and the Informed Consent Form:

Which individual signs as a witness if the HIPAA

Authorization is only available in English?

(98\% correct)

Must a low English fluency patient sign the HIPAA

Authorization form if it is only available in English?

(80\% correct)

Correct response rates were less than $80 \%$ for the clinical scenario questions regarding the use of family interpretation for consent purposes (Scenario \#1) and appropriate use of the MARTTI (video interpretation) device (Scenario \#3). In order to allow for family interpretation for consent purposes, as the consenting provider clinical staff must use the Patient Refusal Medical Interpretation form and have the patient and family member sign. The family member will also sign the Informed Consent Form, the Health Insurance Portability and Accountability Act (HIPAA) Authorization Form, and the Short Form. The most common incorrect response to describing the process for family interpretation for consent purposes was the belief that family members can never interpret for clinical trial consent purposes at Cedars-Sinai Medical Center. Furthermore, the most common incorrect response concerning the MARTTI device (Scenario \#3) was that the MARTTI cannot be used for consent because the MARTTI interpreter is not physically present and cannot sign the documents. In fact, the MARTTI interpreter may interpret the consent from English and the patient will sign the Short form in their preferred language, as well as the Bill of Rights and the HIPPA Authorization Form. An in-person second party may serve as a witness and sign the English HIPAA Authorization, Short form in the preferred language and the English version of the Informed Consent Form as a witness.

Only $29 \%$ of staff reported taking the IRB module on consent for non-English speaking persons. Regarding general consenting practices, when counseling patients with preferred languages other than English, $70 \%$ of the staff reported using professional interpreters often or very often. When asked if they used a patients' family member or friend to help consent, $72 \%$ responded never or rarely, and only $12 \%$ of the staff reported asking family or friends to help consent often or very often. $84 \%$ reported never or rarely using staff members to help with consent, and 95\% reported never using other patients to help consent.

In order to ensure understanding for patients with preferred languages other than English, 69\% of research staff reported setting aside extra time during the consenting 
process often or very often. Furthermore, $69 \%$ of research staff felt that they were often or very often able to communicate effectively with patients with preferred languages other than English. 31\% of principal and co-investigators often found it difficult discussing treatment options with these patients, and $38 \%$ often found it difficult discussing prognosis.

A separate web-based survey was sent to translational services staff, including 2 multiple-choice clinical scenarios and 3 questions eliciting previous experience with translating (see Additional file 2). This survey was sent to a total of 4 individuals, with only a single respondent. This individual affirmed that he/she has been asked to interpret for consenting process for clinical trials and affirmed that he/she feels comfortable with interpreting during the consenting process. Interestingly, that individual reported receiving no specific training regarding interpreting for clinical trial consents. Both of the clinical scenario questions were answered incorrectly.

\section{Clinical trial enrollment rates}

There were a total of 12,538 index cancer cases from January 2011 to October 2014 (Table 2). Of these, 90\% $(N=11,280)$ reported English as their primary language. The remaining $10 \%(N=1258)$ of index cancer cases at CSMC preferred a language other than English. Following English, the most common language amongst the index cancer cases was Spanish $(N=383)$, followed by Russian $(N=303)$, Arabic $(N=200)$ and Chinese $(N=86)$. Of note, Chinese included Cantonese, Chao-Chu, and Mandarin. Arabic included Amharic, Arabic and Farsi.

Table 2 illustrates clinical trial enrollment rates broken down by primary language. Among all-comers, enrollment rate in cancer clinical trials was $12 \%(N=1547)$. English speaking patients comprised 92\% $(N=1421)$ of participation in the Cancer Clinical Trials. The remaining $8 \%(N=126)$ of participants in therapeutic cancer clinical trials preferred a language other than English. Enrollment rates were similar for English (13\%), Spanish (11\%), and,

Table 2 Clinical Trial Enrollment Rates by Primary Language

\begin{tabular}{lllll}
\hline & Total Cancer Cases & Enrolled & Enrollment Rate & $P$-Value \\
\hline English & 11,280 & 1421 & $13 \%$ & (ref) \\
Spanish & 383 & 41 & $11 \%$ & 0.8915 \\
Russian & 303 & 16 & $5 \%$ & $0.0017^{*}$ \\
Arabic & 200 & 10 & $5 \%$ & $0.0138^{*}$ \\
Chinese & 86 & 16 & $19 \%$ & 0.5885 \\
Korean & 73 & 14 & $19 \%$ & 0.5028 \\
Armenian & 70 & 7 & $10 \%$ & 0.9937 \\
Other & 143 & 22 & $15 \%$ & 0.9326 \\
TOTAL & 12,538 & 1547 & $12 \%$ & \\
\hline
\end{tabular}

*Indicates enrollment rate is significantly less than the enrollment rate for English speakers $(p<0.05)$
Armenian (10\%) speakers while rates of participation in clinical trials among Chinese (19\%) and Korean (19\%) were the highest. Populations speaking Russian and Arabic had the lowest participation rates at 5\% each, which is significantly less than the enrollment rate for English speakers $(p<0.05$, Table 2).

We also evaluated clinical trial enrollment rates broken down by cancer site (Fig. 1). The most common cancer sites diagnosed were breast, urologic, gastrointestinal and thoracic malignancies. Clinical trial enrollment rates for each of these primary cancer sites were $10 \%$, $11 \%, 11 \%$, and $20 \%$ respectively. There was no statistically significant difference noted for enrollment rates by language within each of the sub-categories, however sample sizes for non-English speakers was likley too small for efficient estimation. The overall rates of enrollment in thoracic malignancies (20\%) and neuro-oncology $(20 \%)$ were significantly greater than all other cancer types $(p<0.01$ for all tests, Fig. 1).

\section{Discussion}

In general, a clinical trial's informed consent form should present clear and concise information about risks and benefits of participation in that trial. For cancer clinical trials in particular, these forms have become increasingly complex, lending to poor understanding of essential elements among all patients [19, 20]. This phenomenon is only exaggerated among the low English fluency population [21]. The primary aim of this paper was to assess the knowledge of proper consenting procedures among research staff and translational services when consenting a low English fluency patient.

Although there are many organizational in-person and web-based trainings focused on the requirements for consenting low English fluency patients, survey participants only answered $64.8 \%$ of the questions correctly. The research nurses and research coordinators collectively had a higher correct response rate compared to the principal and co-investigators. This finding could be reflective of the fact that clinical trial organization and conscription encompasses the majority of the work of research nurses and coordinators. Nonetheless, only $29 \%$ of staff reported taking the required IRB module on consent for non-English speaking persons. Our survey exposed a lack of procedural knowledge surrounding the consenting process in special populations that should be addressed and improved. Also, although translational services play a crucial role in the consenting process for LEP patients, they do not receive any specialized training regarding interpreting for clinical trial consents. These findings are important because our goal should be to enroll $100 \%$ of eligible patients, and acknowledging the gaps in our current system of enrollment provides us with opportunities to improve the process. 


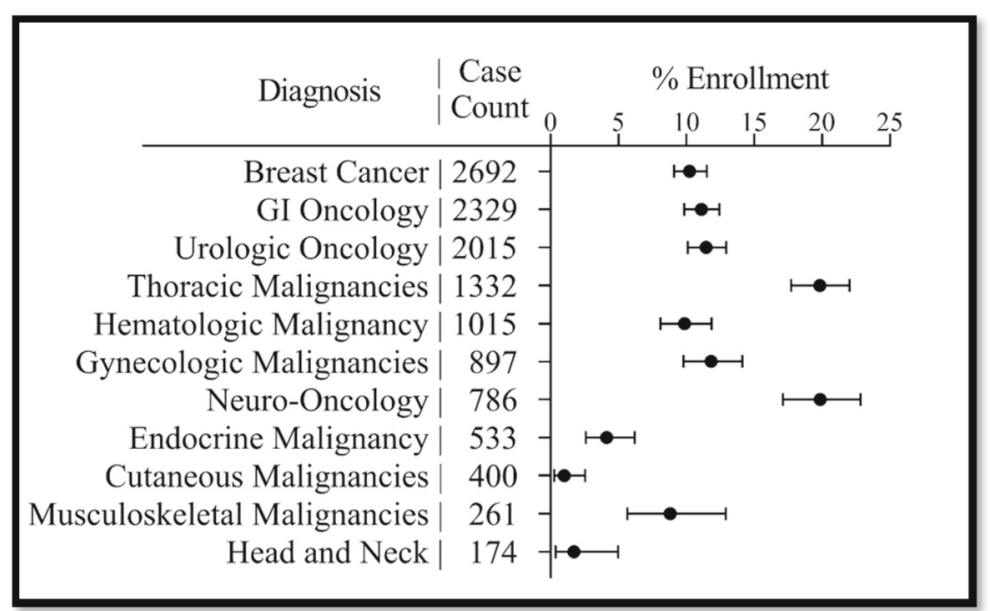

Note: Error bars represent 95\% confidence interval.

Fig. 1 Rates of Clinical Trial Enrollment based on Primary Diagnosis

For our secondary aim we found that among all-comers, enrollment rate in Cancer Clinical Trials was about $12 \%$, which is much higher than the national average of 3\%. English speaking patients comprised $90 \%$ of index cancer cases, and a comparable $92 \%$ of participation in cancer clinical trials. Due to the low total number of low English fluency patients, differences in enrollment were statistically difficult to ascertain. Thus, based on our analysis we are unable to declare superior enrollment rates for English speaking patients compared to all low English-fluency individuals. Enrollment rates were similar for English and Spanish-speaking individuals, which are the 1st and 2nd most represented populations in our cohort, respectively. Spanish is the most spoken foreign language in the United States, and about 38\% of Californians identify as Latino or Hispanic [22]. Perhaps the relative frequency with which Spanish is spoken in California lends a familiarity and comfort among research personnel with Spanish speaking patients. Data on primary and secondary language preferences among consenting providers is lacking, but could provide helpful insight to this finding. Russian and Arabic speaking individuals represent the 3rd and 4th largest populations respectively, and were the only two groups that had statistically significant lower enrollment rates than that of English speaking population, at 5\% each ( $p=0.0017$ for Russian-speakers and $p=0.0138$ for Arabic-speakers). At $19 \%$ each, populations speaking Chinese and Korean had the highest rates of participation, although neither reached statistical significance. Such high rates of participation among Asian-American women is contradictory to prior research [23]. In a pilot study examining the participation of Asian-American women in cancer treatment research, language and the complexity of protocols were identified as major barriers [24]. Furthermore, they found that Asian oncologists were more likely to successfully refer Asian-American women to industry trials than non-Asian oncologists. Thus again, an examination of the demographic characteristics of providers at our institution would be necessary to further investigate this phenomenon. The most common cancer sites diagnosed were breast, urologic, gastrointestinal and thoracic malignancies. There was no statistically significant difference noted for enrollment rates by language within each of the sub-categories as the sample sizes for non-English speakers was too small for efficient estimation.

One of the major weaknesses of this study is the low numbers of each language. Our small sample size may have limited our ability to further classify any differences in enrollment rates. Also, we did not collect information regarding language preferences of the research staff. It would certainly be interesting to see if there is a correlation or preference for enrollment among LEP patients if consented by a coordinator or provider with similar background. We also did not stratify based on eligibility. On average, only about $20 \%$ of patients may even be eligible for cancer clinical trials, and our enrollment rate was $12 \%$ without even considering eligibility. Lastly, among enrolled individuals, we did not examine differences in treatment compliance between groups. While we were unable to show major differences in enrollment rates by preferred language, there may very well be differences in compliance, and this is something that should be explored in future studies.

\section{Conclusions}

In summary, while all staff have access to on-line training, and are required to complete it, those who responded to the survey had merely $65 \%$ competency. Despite this deficiency in procedural knowledge, there 
were no glaring disparities in enrollment of LEP individuals. Still, addressing the deficits in our current system only serves to improve the process of enrolling these individuals with a potential increase in accrual for all. Considerations for future improvement include in-person work-shop training, bi-annual competency exams that require a passing score, or requiring review of IRB guidelines surrounding LEP enrollment prior to any study commencement. Most importantly, research team members should anticipate and prepare language access needs for potential patients, as well as set aside more time to ensure understanding. Again, translational services play a crucial role in the consenting process, yet may often lack specialized training regarding interpreting for clinical trial consents. More attention should be placed on better integrating translation services if possible. For instance, requiring Clinical Trial Consenting training prior to offering such a service. In order to continue to increase enrollment into clinical trials, institutions must provide continuous training opportunities for research staff, engage interpreters and adopt recruitment and study materials in different languages.

\section{Additional files}

Additional files 1: Appendix A (DOCX $90 \mathrm{~kb})$

Additional file 2: Appendix B (DOCX $81 \mathrm{~kb})$

\section{Abbreviations}

HIPPA: Health Insurance Portability and Accountability Act; IRB: Institutional Review Board; LEP: Low English proficiency; MARTTI: My accessible real-time trusted interpreter; SOCCI: Samuel Oschin Comprehensive Cancer Institution

\author{
Acknowledgements \\ The authors would like to acknowledge all individuals who participated in \\ the survey.
}

\section{Funding}

The authors declare that they have received no funding for the research reported.

\section{Availability of data and materials}

The datasets used and/or analyzed during the current study are available from the corresponding author on reasonable request.

\section{Authors' contributions \\ JS was major contributor in developing the survey, analyzing clinical trial enrollment data and writing the manuscript. BR was a major contributor in developing and distributing the survey, analyzing clinical trial enrollment data, and writing the manuscript. JL was a major contributor in developing and distributing the survey, as well as organizing results. CB was a major contributor in statistical analysis. All authors read and approved the final manuscript.}

\section{Ethics approval and consent to participate}

Ethical approval was granted from the Cedars-Sinai Medical Center's Institutional Review Board (IRB) prior to study commencement.

\section{Consent for publication}

Not applicable.

\section{Competing interests}

The authors declare that they have no competing interests

\section{Publisher's Note}

Springer Nature remains neutral with regard to jurisdictional claims in published maps and institutional affiliations.

\section{Author details}

${ }^{1}$ Division of Gynecology Oncology Department of Obstetrics and Gynecology, University of Virginia, P.O. Box 800712, Charlottesville, VA 22908, USA. ${ }^{2}$ Division of Gynecologic Oncology, Department of Obstetrics and Gynecology, Cedars-Sinai Medical Center, Los Angeles, CA, USA.

Received: 25 July 2018 Accepted: 1 October 2018

Published online: 26 October 2018

\section{References}

1. Brawley OW. The study of accrual to clinical trials: can we learn from studying who enters our studies? J Clin Oncol. 2004;22(11):2039-40.

2. Michaels M, Weiss ES, Guidry JA, et al. The promise of community-based advocacy and education efforts for increasing cancer clinical trials accrual. J Canc Educ. 2012:27(1):67-74.

3. Tejeda HA, Green SB, Trimble EL, et al. Representation of African-Americans, Hispanics, and whites in National Cancer Institute cancer treatment trials. J Natl Cancer Inst. 1996;88:812-6.

4. Mannel RS, Moore K. Research: an event or an environment? Gynecol Oncol. 2014;134:441-2.

5. Christian MC, Trimble EL. Increasing participation of physicians and patients from underrepresented racial and ethnic groups in National Cancer Institute- sponsored clinical trials. Cancer Epidemiol Biomarkers Prev. 2003; 12(3):277s-83s

6. Du W, Gadgeel SM, Simon MS. Predictors of enrollment in lung cancer clinical trials. Cancer. 2006:106(2):420-5.

7. Murthy VH, Krumholz HM, Gross CP. Participation in cancer clinical trials: race-, sex-, and age-based disparities. JAMA. 2004:291(22):2720-6.

8. Stewart, et al. Participation in surgical oncology clinical trials: gender-, race/ ethnicity-, and age-based disparities. Ann Surg Oncol. 2007;14(12):3328-34.

9. Giuliano AR, Mokuau N, Hughes C, et al. Participation of minorities in cancer research: the influence of structural, cultural, and linguistic factors. Ann Epidemiol. 2000;10(8 Suppl):S22-34.

10. Corbie-Smith G, Miller WC, Ransohoff DF. Interpretations of 'appropriate' minority inclusion in clinical research. Am J Med. 2004;116(4):249-52.

11. Ford JG, Howerton MW, Bolen S, et al. Information on Recruitment of Underrepresented Populations to Cancer Clinical Trials. In: Evidence Report/ Technology Assessment No. 122 AHRQ Publication No. 05-E019-2. Rockville, MD: Agency for Healthcare Research and Quality; 2005.

12. Baseline study of patient accrual onto publicly sponsored US cancer clinical trials: an analysis conducted for the Global Access Project of the National Patient Advocate Foundation. Philadelphia (PA): Coalition of Cancer Cooperative Groups; 2006. Retrieved at http://www.npaf.org/images/pdf/ gap/sept_2006/cccg.pdf.

13. Sateren WB, Trimble EL, Abrams J, et al. How sociodemographics, presence of oncology specialists, and hospital cancer programs affect accrual to cancer treat- ment trials. J Clin Oncol. 2002;20(8):2109-17.

14. Wendler D, Kington R, Madans J, et al. Are racial and ethnic minorities less willing to participate in health research? Public Libr Sci Med. 2006;3(2):e19.

15. Comis R, Aldige C, Stovall E, Krebs L, Risher P, Taylor H. A quantitative survey of public attitudes towards cancer clinical trials. 2000.Available at: http:// www.asco.org/ac/1,1003,_12-002636-00_18-002-00_19-00100188,00. asp?Abstract|D=100188\&cat=\&parent=\&returnpid $=$.

16. Comis RL, Miller JD, Aldigé CR, Krebs L, Stoval E. Public attitudes toward participation in cancer clinical trials. J Clin Oncol. 2003;21(5):830-5.

17. Killien M, Bigby JA, Champion V, et al. Involving minority and underrepresented women in clinical trials: the National Centers of excellence in Women's health. J Women's Health Gender Based Med. 2000;9(10):1061-70.

18. Nguyen TT, Somkin CP, Ma Y. Participation of Asian-American women in cancer chemoprevention research: physician perspectives. Cancer. 2005; 104(12 Suppl):3006-14. 
19. Berger O, Gronberg BH, Sand K, Kaasa S, Loge JH. The length of consent documents in oncological trials is doubled in twenty years. Ann Oncol. 2009;20(2):379-85.

20. Schumacher A, Sikov WM, Quesenberry MI, Safran H, Khurshid H, Mitchell $\mathrm{KM}$, et al. Informed consent in oncology clinical trials: a brown University oncology research group prospective cross-sectional pilot study. PLoS One. 2017;12(2):e0172957.

21. Breese PE, Burman WJ, Goldberg S, Weis SE. Education level, primary language, and comprehension of the informed consent process. J Empir Res Hum Res Ethics. 2007;2(4):69-79.

22. U.S. Census Bureau, 2011 American Community Survey: Language Use in the United States: 2011. Retrieved from: census.gov/quickfacts/CA

23. Alexander GA, Chu KC, Ho RC. Representation of Asian-Americans in clinical cancer trials. Ann Epidemiol. 2000;10:561-7.

24. Nguyen TT, Smokin CP, Ma Y, Fung L, Ngyuen T. Participation of Asian American women in Cancer treatment research: a pilot study. J Natl Cancer Inst Monogr. 2005;35:102-5.

Ready to submit your research? Choose BMC and benefit from:

- fast, convenient online submission

- thorough peer review by experienced researchers in your field

- rapid publication on acceptance

- support for research data, including large and complex data types

- gold Open Access which fosters wider collaboration and increased citations

- maximum visibility for your research: over $100 \mathrm{M}$ website views per year

At $\mathrm{BMC}$, research is always in progress.

Learn more biomedcentral.com/submissions 